\title{
Correction to: A new analytical model for switching time of a perforated MEMS switch
}

\author{
K. Guha ${ }^{1}$ (D) N. M. Laskar ${ }^{1} \cdot$ H. J. Gogoi ${ }^{1} \cdot$ K. L. Baishnab ${ }^{1} \cdot$ K. Srinivasa Rao ${ }^{2} \cdot$ N. P. Maity ${ }^{3}$
}

Published online: 10 May 2018

(C) Springer-Verlag GmbH Germany, part of Springer Nature 2018

\section{Correction to: Microsystem Technologies https://doi.org/10.1007/ s00542-018-3803-8}

Unfortunately, a co-author's name was not listed in the original publication. The missing author name and affiliation is given below:
N. P. Maity

Department of Electronics and Communication Engineering,

Mizoram University (A Central University, Govt. of India),

Aizawl-796004, India.

The original article can be found online at https://

doi.org/10.1007/s00542-018-3803-8.

\section{K. Guha}

koushikguha2009@gmail.com

1 Department of Electronics and Communication, National Institute of Technology, Silchar, India

2 Micro Electronics Research Group, Department of ECE, KL University, Guntur, AP, India

3 Department of Electronics and Communication Engineering, Mizoram University (A Central University, Govt. of India), Aizawl 796004, India 